\title{
BMJ open Sex work and HIV in Cambodia: trajectories of risk and disease in two cohorts of high-risk young women in Phnom Penh, Cambodia
}

To cite: Page $\mathrm{K}$, Stein $\mathrm{E}$, Sansothy N, et al. Sex work and HIV in Cambodia: trajectories of risk and disease in two cohorts of high-risk young women in Phnom Penh, Cambodia. BMJ Open 2013;3:e003095 doi:10.1136/bmjopen-2013003095

- Prepublication history for this paper is available online. To view these files please visit the journal online (http://dx.doi.org/10.1136/ bmjopen-2013-003095).

MC is currently at Marie Stopes International in Phnom Penh, Cambodia

Received 23 April 2013 Accepted 8 August 2013

For numbered affiliations see end of article.

Correspondence to Dr Kimberly Page; kpage@psg.ucsf.edu

\section{ABSTRACT}

Objectives: HIV prevalence among Cambodian female sex workers (FSW) is among the highest in Southeast Asia. We describe HIV prevalence and associated risk exposures in FSW sampled serially in Phnom Penh, Cambodia (Young Women's Health Study (YWHS)), before and after the implementation of a new law designed to combat human trafficking and sexual exploitation.

Design: Cross-sectional analysis of baseline data from two prospective cohorts.

Setting: Community-based study in Phnom Penh, Cambodia.

Participants: Women aged 15-29 years, reporting $\geq 2$ sexual partners in the last month and/or engaged in transactional sex in the last 3 months, were enrolled in the studies in 2007 ( $\mathrm{N}=161$; YWHS-1), and 2009 ( $\mathrm{N}=220$; YWHS-2) following information sessions where 285 and 345 women attended.

Primary outcomes: HIV prevalence, sexual risk behaviour, amphetamine-type stimulant (ATS) and alcohol use, and work-related factors were compared in the two groups, enrolled before and after implementation of the new law.

Results: Participants in the two cohorts were similar in age (median 25 years), but YWHS-2 women reported fewer sex partners, more alcohol use and less ATS use. A higher proportion of YWHS-2 compared with YWHS1 women worked in entertainment-based venues (68\% vs $31 \%$, respectively). HIV prevalence was significantly lower in the more recently sampled women: $9.2 \%(95 \%$ Cl $4.5 \%$ to $13.8 \%$ ) vs $23 \%$ (95\% Cl $16.5 \%$ to $29.7 \%$ ).

Conclusions: Sex work context and risk have shifted among young FSW in Phnom Penh, following implementation of anti-prostitution and anti-trafficking laws. While both cohorts were recruited using the same eligibility criteria, more recently sampled women had lower prevalence of sexual risk and HIV infection. Women engaging more directly in transactional sex have become harder to sample and access. Future prevention research and programmes need to consider how new policies and demographic changes in FSW impact HIV transmission.

\section{ARTICLE SUMMARY}

Article focus

- HIV prevalence and incidence in two serial samples of young female sex workers (FSW) in Phnom Penh, Cambodia (2007-2008, and 2009-2010).

- Comparison of baseline risk and HIV outcomes, including sexual behaviour, drug and alcohol use in the two cohorts sampled before and after implementation of antitrafficking and sexual exploitation laws in 2008.

- Impact of antitrafficking and sexual exploitation legislation on FSW and HIV risk.

Key messages

- Women sampled using the same eligibility criteria and outreach methods differed with respect to risk exposures and HIV outcomes.

- Changes in sex work typology and environment are evident after enactment of the antitrafficking laws, including very few brothel-based FSW and significantly more FSW based in the entertainment sector.

- Shifts in the context of sex work and risk highlight the ongoing need and challenges for HIV and drug prevention for young women engaged in sex work.

Strengths and limitations of this study

- Two comparably sampled groups of young FSW suggest changing trends in HIV risk.

- Comparison of cross-sectional samples is ecological and does not prove temporal effects.

- Criminalisation and suppression of sex work and a flourishing entertainment-based sex work industry set a new and conflicting stage for HIV prevention.

\section{INTRODUCTION}

There has been a significant decline in HIV prevalence in Cambodia since the epidemic peaked around 2000 , a success widely attributed to measurable increases in condom 
use, declines in the number and frequency of commercial sex transactions reported by men, access to HIV voluntary counselling and testing and uptake of antiretroviral therapy. ${ }^{1-3}$ In 2010, the National Center for HIV/AIDS, Dermatology and STDs (NCHADS) revised the national estimate of HIV prevalence to $0.8 \%$ (in 15-year-olds to 49-year-olds), reflecting a significant decline after the peak estimate of $2.4 \%$ in $1998 .^{4}$ However, HIV prevalence in Cambodian women, especially young women, is among the highest in Southeast Asia and heterosexual sex remains the main route of transmission. ${ }^{5-9}$ Since 2006, women have accounted for over half $(52 \%)$ of all HIV infections in Cambodia, ${ }^{10}$ higher than in Asia and the Pacific in general (35\%). ${ }^{11}$ Limited income generating activities, a highly mobile workforce, trafficking in women and girls and widespread transactional sex, poverty and sexually transmitted infections (STI) have been identified as key drivers of the epidemic among female sex workers

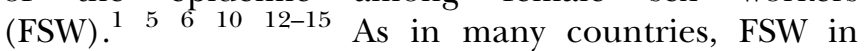
Cambodia can be hard to reach and difficult to provide prevention services to. In recent years, significant economic and policy changes have affected the sex work landscape, with notable shifts in sex work venues, typologies and more women being engaged in transactional sex than ever before. ${ }^{16-20}$

Until 2008, FSW in Cambodia were categorised as 'direct' and were mostly brothel-based, or 'indirect'. Indirect FSW were distinguished from direct FSW, generally working in entertainment establishments as beer promotion girls, waitresses, hostesses or karaoke girls, for example, and engaged in occasional transactional sex for supplementary income. ${ }^{21-23}$ In 1997, an estimated 5300 women worked in the entertainment/ service sector and 6000 were brothel-based FSW. The number of women involved in entertainment-based sex work has grown dramatically in recent years in Cambodia. Until 2008, the estimated number of women engaged in sex and entertainment work was stable (12 762 women were enumerated in 2008); however, by 2012, this had increased dramatically to an estimated 41622 women, a more than threefold increase from the 2008 estimate (NCHADS, personal communication). The reasons for this growth have not been explored in detail, but may be associated with changing economic factors during this time in Cambodia. Following the passage and implementation of the 'Law on Suppression of Human Trafficking and Sexual Exploitation' in February 2008, brothel-based sex work was banned, and the most direct effect was on direct sex trade, which went 'underground', or women moved into indirect work. ${ }^{10}$ Along with the overt enforcement against FSW, the 2008 antitrafficking legislation had other consequences. For instance, official terminology used by governmental and nongovernmental organisations (NGO) to describe FSW labelled all women engaged in sex and entertainment work as 'entertainment workers', or EW. ${ }^{\mathrm{i}}$ Historically, brothel-based FSW were easily accessed and monitored for HIV prevention efforts, including HIV and behavioural surveillance. NGOs working in HIV prevention reported that as transactional sex was displaced to a wider range of settings, women at highest risk became harder to reach for both prevention and service delivery. ${ }^{162425}$ These factors pose significant challenges to HIV prevention and threaten to undermine progress achieved to date.

HIV prevalence is extremely high among Cambodian FSW with prevalence among younger women being particularly troubling as their infection is likely to be more recent and indicative of incidence. ${ }^{58921}$ A cornerstone of HIV prevention in Cambodia was the $100 \%$ Condom Use campaign ${ }^{26} 27$ primarily directed at brothel-based FSW. With changes in sex work venues, this prevention approach is quite likely to be less effective, failing to reach the large number of women now engaged in transactional sex in entertainment establishments. Indeed, measures of self-reported condom use have declined according to the monitoring data reported by UNAIDS. ${ }^{10}$ New risk factors have also emerged, especially amphetamine-type stimulant (ATS) use, in the form of 'yama', ( pills) and 'ice' (a crystalline form) ${ }^{28-38}$ ATS use is associated with increased sexual risk behaviour and STI incidence among these young women, ${ }^{5} 39$ similar to that seen in other populations and locales. ${ }^{40-44}$

We conducted two prospective studies of high-risk young women engaged in transactional sex in Phnom Penh, the principal research questions focused on estimating HIV and STI prevalence and incidence and associated risk factors. The first, Young Women's Health Study (YWHS-1), was conducted in 2007-2008 and the second, YWHS-2, in 2009-2010. ${ }^{5} 16394546$ In this paper, we explore the changing HIV risk landscape by comparing and contrasting the two cohorts of FSW sampled prior to, and following, legislative changes designed to combat human trafficking and sexual exploitation in Cambodia. We theorise that the demographic characteristics and HIV risk of FSW has shifted as a result of sociolegal change induced by the implementation of the new legislation.

\footnotetext{
'The term 'female sex worker' is no longer used in Cambodia. Terminology was changed in 2008 to designate high-risk women working in service and entertainment venues as 'entertainment workers' or EWs. No new HIV surveillance data has been published on FSW, and Behavioral Surveillance Survey (BSS) methods have been changed to recognise only indirect sex workers-'EW', and determining whether or not they are selling sex by the average number of reported sex partners per week (10. UNAIDS. Cambodia Country Progress Report: Monitoring the Progress towards the Implementation of the Declaration of Commitment on HIV and AIDS. Reporting period: January 2010-December 2011. Prepared by National AIDS Authority for United Nations General Assembly Special Session (UNGASS). http://www.unaids.org/en/regionscountries/countries/ cambodia/ accessed 28 December 2012.
} 


\section{METHODS}

Study setting

YWHS-1 and YWHS-2 were both prospective studies of young women engaged in sex work in Phnom Penh, Cambodia. Methods have been described previously in detail. $^{5} 39$ Both studies were led by a multidisciplinary collaborative prevention research group from NCHADS, the Cambodian Women's Development Association (CWDA), the University of California in San Francisco (UCSF) in the USA and the Kirby Institute at the University of New South Wales (UNSW) in Australia.

\section{Study population and recruitment}

The target population in both studies was young women engaged in transactional sex in Phnom Penh. Inclusion criteria were aged 15-29 years, Khmer language comprehension, $\geq 2$ different sexual partners in the last month or engaged in transactional sex (sex in exchange for money, goods, services or drugs) within the last 3 months, no plans to move in the next 12 months, biologically female and able to provide voluntary informed consent. YWHS-1 aimed to sample 160 women to provide $80 \%$ power to estimate a point prevalence of $\mathrm{HIV}$ at $15 \%$ with a $95 \%$ CI of $9.7 \%$ to $23 \%$. Based on results of YWHS-1, YWHS-2 aimed to sample 220 women to detect an estimated HIV prevalence of $23 \%$ (95\% CI $17.3 \%$ to $30.5 \%)$.

The recruitment and enrolment procedures were the same in both studies. ${ }^{5}$ CWDA field assistants provided study information and conducted eligibility screening via information meetings in neighbourhoods where sex work was prevalent. Eligible women were invited to a community location used by various sex-worker organisations where study information was described in more detail and written informed consent was obtained. Enrolled participants were given appointment cards to present to the YWHS clinic field-site and free transportation was offered. In both studies, women were remunerated US $\$ 5$ at each study visit for their participation time.

\section{Data collection}

All data collection occurred at the YWHS clinic, which was staffed by a physician, nurses, counsellors and a laboratory technician. A structured questionnaire was administered in Khmer by trained interviewers. Survey items were similar in both studies and covered sociodemographic characteristics, occupational and sexual risk history, alcohol and drug use. HIV testing was conducted at each visit. In YWHS-1, urine specimens were tested for Chlamydia trachomatis (CT) and Neisseria gonorrhoea (GC). In YWHS-2, women were tested for HPV infection. STI treatment was provided at no cost, and women with HIV and HPV infection were referred to a local provider for free medical evaluation and treatment.

\section{Laboratory testing}

HIV serology was performed using two rapid tests: Uni-Gold Recombigen HIV rapid HIV test (Trinity
Biotech USA, Jamestown, New York, USA) and the Clairview HIV 1/2 STAT-PAK (Inverness Medical Diagnostics, Waltham, Massachusetts, USA). HIV positive and discordant samples were confirmed by HIV-1 immunoblot. CT and GC were assessed from urine samples using the BDProbeTec strand displacement amplification assay (Becton Dickinson, Sparks, Maryland, USA) at the NCHADS STD laboratory. ${ }^{5}$ Cervical specimens for HPV testing were collected using a standard cytobrush. ${ }^{47}$ Client-centred risk reduction counselling was provided in association with all testing.

\section{Ethical review}

The study protocols were reviewed and approved by the Institutional Review Board of the Committee on Human Research at UCSF, the Cambodian National Ethics Committee and the UNSW Human Research Ethics Committee in accordance with ethical standards (institutional and national) and with the Helsinki Declaration of 1975 , as revised in 2000 .

\section{Measures}

Both studies aimed to estimate HIV infection, ATS use and sexual risk behaviour and included questions on sociodemographic factors, work history, income and duration of sex work, and whether they currently had an employer (manager, boss or supervisor). Women were asked if they had ever and/or were currently working: as a beer promoter, in a beer garden, as a waitress or hostess in a karaoke bar, nightclub or snooker bar, in a massage parlour, brothel, as a freelance sex worker using space at a brothel, as a freelance sex worker in the park or on the street or to specify 'other' location. They were asked about age at first sex, the number of partners (last month) and condom use with last partners (paying and non-paying). Paying partners were defined as male clients with whom respondents traded sex for money, goods or drugs. Condom use was classified as 'consistent' if the participant reported always using a condom. Participants were asked about the number of days on which alcohol was drunk and the number of days on which they were 'affected' by alcohol or were 'drunk' in the past month. ATS use (ever and last 3 months) was assessed with questions regarding use of yama and crystal (ice).

\section{Analyses}

Prevalence estimates were calculated using exact binomial CI. The $\chi^{2}$ and Fisher's exact tests were used to examine differences in baseline sociodemographic, occupational, sexual and alcohol/drug use exposures and prevalent HIV and STI between the two cohorts. The only longitudinal data to be compared related to HIV incidence. The HIV incidence rate was calculated using the number of seroconversions/100 person-years of observation (PYO) assuming a Poisson distribution. Analyses were performed using STATA V.9.0 (STATA, College Station, Texas, USA). 


\section{RESULTS}

In YWHS-1, 285 women attended community information sessions, $161(56 \%)$ eligible women were recruited to the group information/consent meeting and 160 (99\%) consented to participate. In YWHS-2, 220 (64\%) women consented out of 345 who attended the information sessions. Sixty-seven women from YWHS-1 also enrolled in YWHS-2; they were not included in the YWHS-2 comparison group, leaving 153 in the analysis. Table 1 shows the baseline sociodemographic and occupational factors, as well as the sexual and substance use risk exposures, in the two cohorts. The cohorts were similar with respect to age (median 25 years) and age of sexual debut (median 17 and 18 years, respectively), but differed significantly in years of education and marital status. Compared with women in YWHS-1, women in YWHS-2 had more education (median of 5 years (IQR 2, 7) vs 2 years $(\mathrm{IQR} 0,4)$ ) and were more likely to be married or cohabiting with a partner $(31.4 \%$ vs $15 \%$, respectively).

Women in YWHS-2 had been involved in sex work for significantly less time (median of 3 years (IQR 1.7, 5)) than YWHS-1 women (median of 4.3 years (IQR 2.5, $6.3)$ ). More YWHS-2 women were currently (last 30 days) working in entertainment venues and fewer in brothels, or as freelance FSW (including in parks, guest houses or on the street). These differences were also reflected in the significantly higher proportion of YWHS-2 women who reported having a manager or boss $(81.6 \%)$ compared with YWHS-1 women (46\%). Figure 1 shows the distribution and range of work venues women reported 'ever' working in. Women in YWHS-2 also reported significantly fewer sexual partners in the past 30 days: a median of 5 compared with 30 in YWHS-1 (table 1). Despite these differences, women in the two samples reported similar income distributions. Self-reported consistent condom use, with both paying and non-paying partners, did not differ between cohorts. Alcohol and ATS use differed significantly: women in YWHS-2 reported more alcohol use but fewer days drunk in the past month than those in YWHS-1; fewer women in YWHS-2 reported ever using ATS, although recent use was similar in both groups (table 1). Alcohol and ATS use varied by cohort and work venue: entertainmentbased women in YWHS-2 reported less of both, whereas brothel-based and freelance-based women in YWHS-2 reported significantly more ATS use (figure 2).

HIV prevalence was significantly $(\mathrm{p}<0.01)$ lower in women sampled in YWHS-2 compared with those in YWHS-1: $9.2 \%$ (95\% CI $4.5 \%$ to $13.8 \%$; $\mathrm{p}<0.01$ ) vs $23 \%$ (95\% CI $16.5 \%$ to $29.7 \%$; table 2$)$. When the 67 women who had participated in both samples were included in YWHS-2, HIV prevalence was $15.5 \%$ (95\% CI $10.6 \%$ to 20.3\%). HIV incidence was also lower in YWHS-2: 0.8/ 100 PYO (95\% CI 0.1 to 6.0$)$ vs $3.6 / 100$ PYO (95\% CI 1.2 to 11.1$)$, but not significantly $(\mathrm{p}=0.26)$. In YWHS-1, prevalence of Chlamydia infection was $11.5 \%$ (95\% CI $6 \%$ to $17.1 \%$ ) and that of Gonorrhoea infection was
$7.8 \%$ (95\% CI 3.5\% to 12.3\%). Women in YWHS-2 were not tested for these STI, but $41.1 \%$ were HPV-positive. HIV prevalence differed significantly by work venue and by cohort, but over $30 \%$ of freelance-based women tested positive in both cohorts (table 2).

In both cohorts, $20 \%$ reported being tested for HIV in the past 3 months but more YWHS-2 women had a history of testing (table 3). More women in YWHS-1 reported not knowing their HIV test results: 11 of the 84 women $(13.1 \%)$ who reported being negative tested positive and 4 of 12 women $(33.3 \%)$ who reported that they did not know their previous HIV results tested positive. In YWHS-2, 5 of 114 women (4.4\%) who reported testing negative, and 2 of $4(50 \%)$ who did not know their previous results, tested positive. Among women who reported no history of HIV testing, 31\% (18/58) and $12.9 \%(4 / 31)$ tested HIV positive in YWHS-1 and YWHS-2, respectively.

\section{DISCUSSION}

In these two samples of young FSW, recruited using the same eligibility criteria and outreach methods, we observed important differences in sociodemographics, risk exposures and HIV infection outcomes. Most notably, women sampled more recently were more educated, had fewer sex partners, less time working in sex work and had significantly lower prevalence of HIV. Where women worked was also very different in the two cohorts: a much higher proportion of women sampled in 2009-2010 compared with 2007-2008 worked in entertainment-based establishments and fewer were brothel-based or freelance FSW. These differences point to the notable changes in sex work typology and environment that occurred following the enactment and enforcement in 2008 of antitrafficking legislation in Cambodia. ${ }^{16}$ Brothel closures and increases in policing have been acknowledged as a cause of significant social and occupational upheaval among FSW, driving many women, especially former brothel-based FSW, "underground'. ${ }^{10}$ Government agencies and NGOs in Phnom Penh have reported negative impacts of the legislation on FSW including: displacement and harassment and reduced access to condoms and healthcare. ${ }^{10} 2024$ In our qualitative research, women confirmed these impacts, describing how they moved to new venues or locales for sex work transactions including apartments or houses rented by brothel owners following brothel closures ${ }^{16}$ raising concerns about the increased risks of HIV transmission as a result of the increasingly clandestine nature of direct sex work. The significant increases in the number of women involved in sex work also warrant attention.

The differences in HIV prevalence, risk profiles and sex work environments reported by these two samples are consistent with quantitative and qualitative research demonstrating how sociopolitical and environmental factors can increase vulnerability to HIV among FSW. $^{48-51}$ 
Table 1 Selected sociodemographic characteristics, occupational and risk exposures in two cohorts of high-risk young women in Phnom Penh, Cambodia: YWHS-1 (2006-2007) and YWHS-2 (2009-2010)

\begin{tabular}{|c|c|c|c|c|c|}
\hline \multirow[b]{2}{*}{ Characteristic } & \multicolumn{2}{|c|}{$\begin{array}{l}\text { YWHS-1 N=160 } \\
\text { Prevalence of } \\
\text { characteristic }\end{array}$} & \multicolumn{2}{|c|}{$\begin{array}{l}\text { YWHS-2 N=153* } \\
\text { Prevalence of } \\
\text { characteristic }\end{array}$} & \multirow[b]{2}{*}{ p Value } \\
\hline & $\overline{\mathbf{N}}$ & Per cent & $\mathbf{N}$ & Per cent & \\
\hline Age (years, median (IQR)) & \multicolumn{2}{|c|}{$25(21-27)$} & \multicolumn{2}{|c|}{$25(22-28)$} & 0.56 \\
\hline $16-18$ & 13 & 8.1 & 11 & 7.2 & 0.86 \\
\hline $19-24$ & 64 & 40.0 & 58 & 37.9 & \\
\hline $25-29$ & 83 & 51.8 & 84 & 54.9 & \\
\hline \multicolumn{6}{|l|}{ Marital status } \\
\hline Never married & 57 & 35.6 & 38 & 24.8 & $<0.01$ \\
\hline Married-living together & 24 & 15.0 & 48 & 31.4 & \\
\hline Widowed/divorced/separated & 79 & 49.4 & 67 & 43.8 & \\
\hline \multicolumn{6}{|l|}{ Education (years) } \\
\hline None & 64 & 40.0 & 23 & 15.0 & $<0.01$ \\
\hline Primary (1-6 years) & 82 & 51.3 & 91 & 59.5 & \\
\hline Secondary $(7+$ years $)$ & 14 & 8.8 & 39 & 25.5 & \\
\hline Age at first sex (median (IQR)) & \multicolumn{2}{|c|}{$17(16-18)$} & \multicolumn{2}{|c|}{$18(16-19)$} & 0.03 \\
\hline$\leq 15$ & 32 & 20.1 & 22 & 14.5 & 0.19 \\
\hline$>15$ & 127 & 79.9 & 130 & 85.5 & \\
\hline Length of employment as FSW (years, median (IQR)) & \multicolumn{2}{|c|}{$4.3(2.5-6.3)$} & \multicolumn{2}{|c|}{$3(1.7-5)$} & $<0.01$ \\
\hline \multicolumn{6}{|l|}{ Current employment venue (last 30 days) } \\
\hline Entertainment & 51 & 31.9 & 113 & 74.3 & $<0.01 \dagger$ \\
\hline Brothel & 23 & 9.2 & 3 & 2.0 & \\
\hline Freelance & 59 & 39.3 & 29 & 19.1 & \\
\hline Other/multiple & 27 & 16.9 & 7 & 4.6 & \\
\hline \multicolumn{6}{|l|}{ Have a manager, boss or supervisor } \\
\hline No & 82 & 53.6 & 28 & 14.4 & $<0.01$ \\
\hline Yes & 71 & 46.4 & 124 & 81.6 & \\
\hline \multicolumn{6}{|l|}{ Income in past month (US\$) } \\
\hline Less than 100 & 68 & 42.5 & 50 & 32.9 & 0.18 \\
\hline $100-150$ & 35 & 21.9 & 43 & 29.3 & \\
\hline Over 150 & 57 & 35.6 & 59 & 38.8 & \\
\hline Number of sex partners in last month (median (IQR)) & \multicolumn{2}{|c|}{$30(10-90)$} & \multicolumn{2}{|c|}{$5(3-13)$} & $<0.01$ \\
\hline$\leq 10$ & 45 & 28.1 & 112 & 73.2 & $<0.01$ \\
\hline $11-50$ & 53 & 33.1 & 41 & 26.8 & \\
\hline$>50$ & 62 & 38.8 & 0 & 0 & \\
\hline \multicolumn{6}{|l|}{ Condom use with last paying partner } \\
\hline Consistent (always) & 108 & 85.7 & 86 & 87.8 & 0.66 \\
\hline Inconsistent & 18 & 14.3 & 12 & 12.2 & \\
\hline Condom use with last non-paying partner & & & & & \\
\hline Consistent (always) & 7 & 20.6 & 10 & 18.2 & 0.78 \\
\hline Inconsistent & 27 & 79.4 & 45 & 81.8 & \\
\hline Number of days drink alcohol (last month) & & $-30)$ & & $-28)$ & 0.76 \\
\hline $0-4$ & 65 & 40.6 & 36 & 23.5 & $<0.01$ \\
\hline $5-19$ & 25 & 15.6 & 42 & 27.5 & \\
\hline$\geq 20$ & 70 & 43.7 & 75 & 49.0 & \\
\hline Number of days drunk (last month) & & -20) & & 10) & 0.07 \\
\hline $0-4$ & 89 & 55.6 & 86 & 56.2 & $<0.01$ \\
\hline $5-19$ & 33 & 20.6 & 50 & 32.7 & \\
\hline$\geq 20$ & 38 & 23.7 & 17 & 11.1 & \\
\hline ATS use (ever) & & & & & \\
\hline No & 92 & 57.5 & 107 & 69.9 & 0.02 \\
\hline Yes & 68 & 42.5 & 46 & 30.1 & \\
\hline ATS use (last 3 months) & & & & & \\
\hline No & 116 & 73.4 & 117 & 76.5 & 0.54 \\
\hline Yes & 42 & 26.6 & 36 & 23.5 & \\
\hline Ever used any drug prior to/during sex & & & & & \\
\hline No & 109 & 68.1 & 117 & 76.5 & 0.10 \\
\hline Yes & 51 & 31.9 & 36 & 23.5 & \\
\hline
\end{tabular}




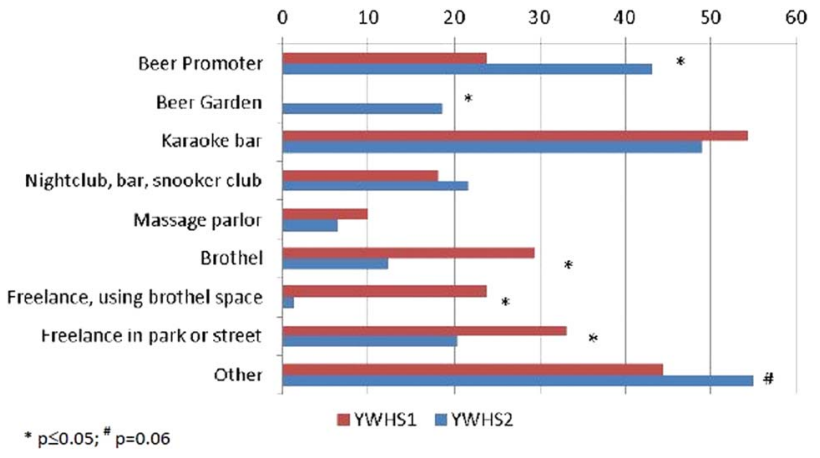

Figure 1 Venues where women in Young Women's Health Study (YWHS)-2 and YWHS-2 reported ever working.

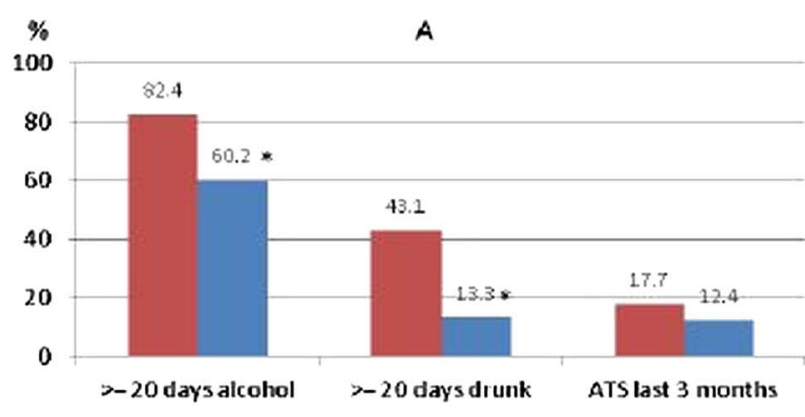

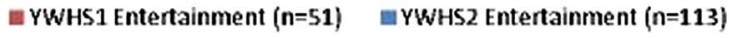
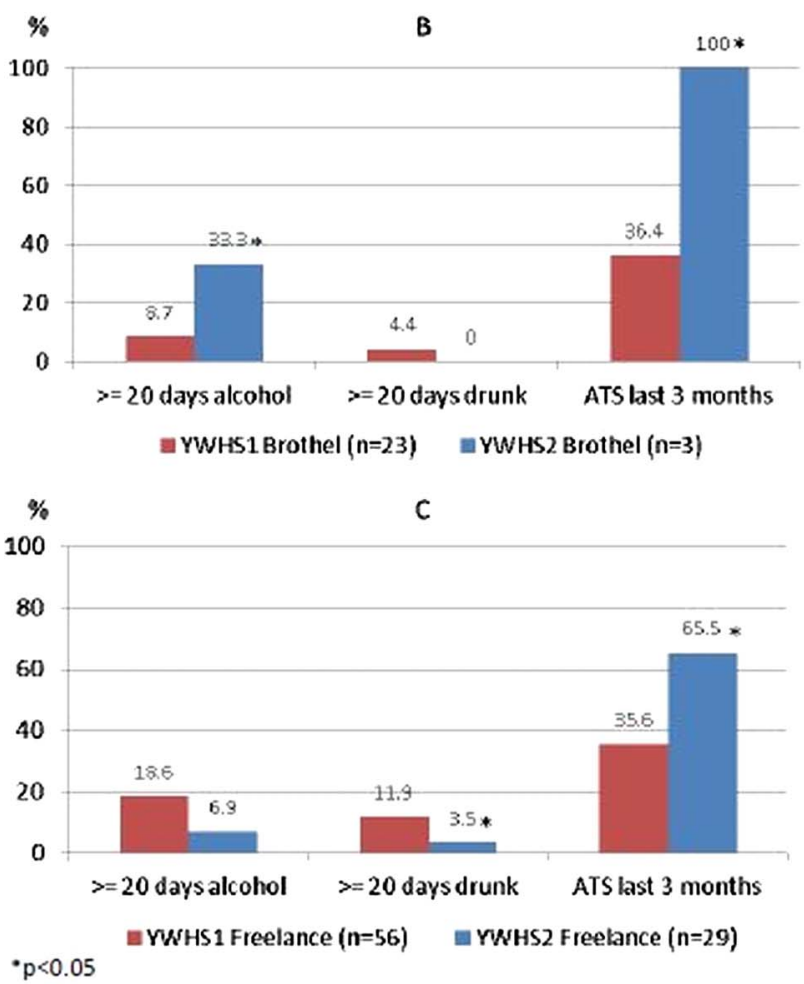

Figure 2 Alcohol use in the past month and amphetamine-type stimulant use in the past 3 months reported by women in the Young Women's Health Study (YWHS)-1 and YWHS-2 by work venue: (A) entertainment-based; (B) brothel-based; (C) freelance.
The time period in which these two cohorts were sampled corresponded with increased criminalisation of sex work, which impacted the number and settings of transactional sex. These shifts can have mixed effects. First, women engaged in entertainment-based work have lower risk profiles than women engaged in freelance sex work. $^{5}$ The shorter duration of sex work reported by entertainment-based FSW quite likely contributes to the lower HIV prevalence in this group. The protective effects of entertainment-based work may include having a boss or manager; the odds of HIV among women who say they have a boss or manager are lower compared with those among women who do not (OR: 0.40; $95 \%$ CI 0.19 to 0.90$).{ }^{5}$ We also explored these factors in qualitative interviews with FSW. ${ }^{16}$ Brothel-based and entertainmentbased sex workers reported that the 'boss/manager' mitigated the risk of violence from clients and problems with police. Also, women working in entertainment establishments report earning up to three times more (US\$50$\$ 60$ or in US $\$ 200000-U S \$ 240000$ Cambodian Riel) per client than women who worked in brothels or streets and parks. ${ }^{16}$ This is substantiated by the two cohorts' report of similar income levels despite differences in the number of sex partners. It is also possible that entertainment-based FSW have lower risk partners than brothel-based and freelance FSW. We believe that despite the lower prevalence of HIV and the lower number of male sex partners reported by this growing group of FSW, there is a significant potential for amplified transmission of HIV at a population level, due principally to the extraordinary growth in the size of the population engaged in sex work. The numbers enumerated by the government are likely to include a high proportion of entertainmentbased FSW who have significantly lower risk overall. But it is unclear as to how well the population of high-risk women, those previously working in brothels, who were not apparent or represented in our latter sample, are apparent in the census. These now-displaced women may or may not be counted, but they are highly likely to be engaged in clandestine transactional sex, as suggested by our qualitative research. Women sampled in YWHS-2 reflect the majority of the growing population of low-risk EW: they report fewer exposures and have lower HIV prevalence; however, our qualitative data also suggest that unprotected sex, length of sexual transactions and sex in risky environments may have increased. ${ }^{16} 45$ While we cannot establish that the criminalisation of sex work causes an increase in population HIV risk from these limited data, the results from these studies correspond to marked shifts in the demographic and risk population that should be investigated more thoroughly.

The two cohorts also showed differences in drug and alcohol use exposures. Our group has identified ATS use as a significant independent risk factor for HIV-related risk behaviour including the number of sex partners (adjusted risk ratio: $1.49 ; 95 \%$ CI 1.0 to 2.21 ) and incident STI (AOR: $5.41 ; 95 \%$ CI 1.15 to 25.48 ). ${ }^{39}$ Alcohol use is also emerging as a potential HIV-related risk factor, ${ }^{16}$ 
Table 2 HIV prevalence overall and by current work venue in two cohorts of young high-risk women in Phnom Penh, Cambodia: YWHS-1 (2006-2007) and YWHS-2 (2009-2010)

\begin{tabular}{|c|c|c|c|c|c|}
\hline \multirow[b]{2}{*}{ Characteristic } & \multicolumn{2}{|c|}{ YWHS-1 N=160 } & \multicolumn{2}{|c|}{ YWHS-2* $N=153^{*}$} & \multirow[b]{2}{*}{ p Value } \\
\hline & $\mathbf{N}$ & $\%(95 \% \mathrm{Cl})$ & $\mathbf{N}$ & $\%(95 \% \mathrm{Cl})$ & \\
\hline HIV positive & 37 & 23.1 (16.5 to 29.7$)$ & 14 & 9.2 (4.5 to 13.8$)$ & $<0.01$ \\
\hline \multicolumn{6}{|l|}{ HIV positive by employment venue (n/N) } \\
\hline Entertainment & $5 / 51$ & $9.8(1.5$ to 18.1$)$ & $5 / 113$ & 4.4 (0.6 to 8.2$)$ & $<0.01$ \\
\hline Brothel & $4 / 23$ & 17.4 (1.5 to 33.3$)$ & $0 / 3$ & 0 & \\
\hline Freelance & $22 / 59$ & 37.3 (25.0 to 48.0$)$ & $9 / 29$ & 31.0 (13.8 to 48.2$)$ & \\
\hline Other/multiple & $6 / 27$ & $22.2(6.2$ to 38.3$)$ & $0 / 7$ & 0 & \\
\hline
\end{tabular}

${ }^{*}$ Excludes women who participated in YWHS-1.

YWHS, Young Women's Health Study.

although not well quantified among FSW, especially those working in entertainment establishments (or their male partners). Entertainment venues largely revolve around alcohol, and women working at these are generally employed as hostesses, waitresses, or as 'promoters' such as 'beer promotion girls' in a variety of venues. ${ }^{16}{ }^{21}$ Women who were working in the entertainment sector were more likely to report more days of drinking as well as more days intoxicated than brothel-based or street-based FSW. Alcohol use can be a barrier to effective condom use and condom negotiation in the transactional context. ${ }^{16}{ }^{52}$ Although women in the two samples did not report differences in inconsistent condom use, we have previously found that women who report heavy alcohol use are also significantly more likely to report inconsistent condom use. ${ }^{39}$ Given how entwined drug and alcohol use are with sex work, especially in the growing entertainment-based sector, there is a significant need to better elucidate ways to mitigate HIV-associated risks among women whose livelihood depends on working in these establishments.
Designing and implementing prevention in these contexts will require input not only from working women, but also from the wider business sector, as well as male clients. ${ }^{48} 53-$ 56

The differences in HIV and risk profiles between the women in our two samples, as well as outreach efforts by HIV prevention organisations, may be a result of reaching for the 'low hanging fruit' resulting from substantive increases in the number of women working in entertainment establishments and the increased challenges of engaging women with higher risk and who are HIV infected for the reasons described above. FSW in Phnom Penh have historically been easily accessed for prevention and surveillance efforts. However, recent changes in the sex work landscape suggest that alternative sampling methods, such as respondent-driven sampling, may result in better access to higher risk women who are more hidden and therefore hard to reach in this new legal climate..$^{57}$

HIV prevention remains an important and essential priority for all women engaged in transactional sex.

Table 3 HIV testing history and behaviours in two cohorts of young high-risk women in Phnom Penh, Cambodia: YWHS-1 (2006-2007) and YWHS-2 (2009-2010)

\begin{tabular}{|c|c|c|c|c|c|}
\hline \multirow[b]{2}{*}{ Characteristic } & \multicolumn{2}{|c|}{ YWHS-1 N=160 } & \multicolumn{2}{|c|}{ YWHS-2* N=153* } & \multirow[b]{2}{*}{ p Value } \\
\hline & $\overline{\mathbf{N}}$ & Per cent & $\overline{\mathbf{N}}$ & Per cent & \\
\hline \multicolumn{6}{|l|}{ Ever tested for HIV } \\
\hline No & 58 & 36.5 & 31 & 20.3 & \multirow[t]{2}{*}{$<0.01$} \\
\hline Yes & 101 & 63.5 & 122 & 79.7 & \\
\hline \multicolumn{6}{|l|}{ HIV test in the last 3 months } \\
\hline No & 126 & 79.3 & 119 & 77.8 & \multirow[t]{2}{*}{0.75} \\
\hline Yes & 33 & 20.7 & 34 & 22.2 & \\
\hline \multicolumn{6}{|l|}{ What was the result of the last HIV test? $†$} \\
\hline Negative & 84 & 84.0 & 114 & 93.4 & \multirow[t]{3}{*}{0.04} \\
\hline Positive & 4 & 4.0 & 4 & 3.3 & \\
\hline Do not know & 12 & 12.0 & 4 & 3.3 & \\
\hline \multicolumn{6}{|l|}{ Where was the last HIV test received?† } \\
\hline Public hospital & 35 & 34.7 & 55 & 34.0 & \multirow[t]{4}{*}{0.10} \\
\hline Voluntary testing and counselling centre & 1 & 1.0 & 0 & 0 & \\
\hline NGO clinic & 59 & 58.4 & 54 & 44.3 & \\
\hline Private hospital, clinic or laboratory & 6 & 5.9 & 13 & 10.7 & \\
\hline
\end{tabular}

*Excludes women who participated in YWHS-1.

†Among those who reported being previously tested for HIV.

NGO, non-governmental organisations; YWHS, Young Women's Health Study. 
A recent systematic review confirms that FSW in Asia have the highest odds of infection compared with women of reproductive age in the general population. ${ }^{58}$ In addition to new structural interventions aimed at reducing risk in the work-based environment, the very high prevalence and risk of HIV among FSW in Cambodia suggest a need for combination HIV prevention interventions including biomedical (pre-exposure prophylaxis, microbicides and treatment as prevention), behavioural and development approaches (such as microfinance or income-generating opportunities).$^{59-64}$

Several limitations of these analyses should be noted. First, the results presented here are cross-sectional, and thus the associations do not reflect causality. The comparison of the serial samples is ecological in nature and does not prove temporal effects. The sample sizes are small and thus subject to limitations with respect to generalisability. Many exposures are self-reported and thus may reflect social desirability bias, especially condom use, which we have found has been over-reported based on biomarker data. ${ }^{65}$ On the other hand, we have found that self-reported ATS use is accurate compared with urine toxicology screening, suggesting that measures of drug and alcohol use in this group are accurate. ${ }^{66}$

The results from this analysis provide important insights into recent shifts in the context of sex work and risk in young FSW in Phnom Penh, highlight challenges to HIV prevention in this environment, and also point to the need for more research. Conflicting trends include the criminalisation and suppression of direct sex work while the indirect entertainment-based sex work industry is flourishing, which has potentially set a new stage. Unless there is acknowledgment and access to women who are more directly engaged in sex work, these women will be poorly represented in any national HIV or behavioural surveillance. They will remain hidden and stigmatised, subject to repression, violence and potentially with less access to prevention or care. While the $100 \%$ condom use programme had its criticisms, that policy at least acknowledged the existence and need for HIV prevention at a multisectoral level for FSW. The current sociopolitical climate has potentially reversed these benefits, by denying the existence of FSW. Further in-depth research among FSW, their male clients and the entertainment venue management would help to elucidate the impacts, both positive and negative, of these new laws. The exponential growth of entertainment-based sex work has the potential to result in an expanding HIV epidemic among young women in Cambodia. From a programmatic perspective, entertainment-based FSW are much easier to reach but most likely require different HIV prevention interventions than the $100 \%$ condom use programme. Implementation of research and programmatic efforts that integrate health, social empowerment and safe work environments for HIV prevention remain a high priority for women engaged in sex work in Cambodia. ${ }^{67}$
Author affiliations

${ }^{1}$ Department of Epidemiology and Biostatistics, University of California San Francisco, San Francisco, and Global Health Sciences, San Francisco, California, USA

${ }^{2}$ National Center for HIV/AIDS, Dermatology and STDs (NCHADS), Sangkat Prekleap Russey Keo, Phnom Penh, Cambodia

${ }^{3}$ Cambodian Women's Development Association (CWDA), Phnom Penh, Cambodia

${ }^{4}$ The Kirby Institute (formerly the National Centre in HIV Epidemiology and Clinical Research); University of New South Wales, Darlinghurst, New South Wales, Australia

${ }^{5}$ The Centre for Values, Ethics and the Law in Medicine, The University of Sydney, Camperdown, New South Wales, Australia

${ }^{6}$ Royal University of Fine Arts, Phnom Penh, Cambodia

Acknowledgements The authors would like to acknowledge the co-ordinated efforts and dedication of the research teams at the National Center for HIV/ AIDS, Dermatology, and STDs and the Cambodian Women's Development Agency. We are indebted to all the Cambodian women who agreed to participate in this study and grateful for the privilege to work with them.

Collaborators On behalf of the Young Women's Health Study Collaborative: *John Kaldor, Serey Phal Kien, Kimberly Page, Joel M Palefsky MD Vonthanak Saphonn, Mean Chhi Vun.

Contributors All authors contributed to the design and implementation of the YWHS-1 and YWHS-2 studies. KP, ES, JE and LM compiled the first draft of the manuscript, which was reviewed by NS, M-CC, KS, MC, JM-S, PP and JK The primary statistical analysis was conducted by JE and M-CC; KS and MC provided supplemental data review, and KP reviewed all the data analyses. All authors contributed to and have approved the final manuscript. The YWHS Collaborative is a steering committee which reviewed and approved the study protocols and provided expertise in some or all of the studies' methods and implementation.

Funding US National Institutes of Health. The Young Women's Health Study1 and YWHS-2 were supported by Awards 1R21DA025441 from the National Institute on Drug Abuse, and R01NR010995 from the National Institute of Nursing Research. M-C Couture was also supported by the Canadian Institutes of Health Research (postdoctoral fellowship award). Professors Lisa Maher and John Kaldor are supported by Australian National Health and Medical Research Council (NHMRC) Research Fellowship. The Kirby Institute is affiliated with the Faculty of Medicine, University of New South Wales and is funded by the Australian Government Department of Health and Ageing. The content is solely the responsibility of the authors and does not necessarily represent the official views of the National Institutes of Health, nor the Australian Government. The authors have no conflicts to disclose.

Competing interests None.

Ethics approval UCSF Institutional Review Board; Cambodia National Ethics Committee; University of New South Wales Human Research Ethics Committee.

Provenance and peer review Not commissioned; externally peer reviewed.

Data sharing statement No additional data are available.

Open Access This is an Open Access article distributed in accordance with the Creative Commons Attribution Non Commercial (CC BY-NC 3.0) license, which permits others to distribute, remix, adapt, build upon this work noncommercially, and license their derivative works on different terms, provided the original work is properly cited and the use is non-commercial. See: http:// creativecommons.org/licenses/by-nc/3.0/

\section{REFERENCES}

1. NCHADS. Ministry of Health National Center for HIV, AIDS, Dermatology and STDs. Annual Report 2009: National Centre for HIV/AIDS, Dermatology and STDs. Cambodia 2011. http://www. nchads.org/report.php (accessed 8 Jul 2011).

2. Saphonn V, Sopheab H, Sun LP, et al. Current HIV/AIDS/STI epidemic: intervention programs in Cambodia, 1993-2003. AIDS Educ Prev 2004;16(3 Suppl A):64-77.

3. NCHADS. Behavioral Sentinel Surveillance 2010. Cambodia National Centor for HIV, AIDS. Dermatology and STD Dissemination Conference; 30 December 2010, 2011. 
4. NCHADS. Ministry of Health National Center for HIV, AIDS, Dermatology and STDs. Estimation of the HIV prevalence among the general population in Cambodia. Cambodia: National Centre for HIV/AIDS, Dermatology and STDs,2011. http://www.nchads.org/ index.php?id=20\&event=146 (accessed 8 Jul 2011).

5. Couture MC, Sansothy N, Sapphon V, et al. Young women engaged in sex work in Phnom Penh, Cambodia, have high incidence of HIV and sexually transmitted infections, and amphetamine-type stimulant use: new challenges to HIV prevention and risk. Sex Transm Dis 2011;38:33-9.

6. Sopheab H, Saphonn V, Chhea C, et al. Distribution of HIV in Cambodia: findings from the first national population survey. AIDS 2009;23:1389-95.

7. Sopheab H, Morineau G, Neal JJ, et al. Sustained high prevalence of sexually transmitted infections among female sex workers in Cambodia: high turnover seriously challenges the $100 \%$ condom use programme. BMC Infect Dis 2008;8:167.

8. Sopheab H, Gorbach PM, Gloyd S, et al. Rural sex work in Cambodia: work characteristics, risk behaviours, HIV, and syphilis. Sex Transm Infect 2003;79:e2.

9. Saphonn V, Parekh BS, Dobbs T, et al. Trends of HIV-1 Seroincidence Among HIV-1 Sentinel Surveillance Groups in Cambodia, 1999-2002. J Acquir Immune Defic Syndr 2005;39:587-92.

10. UNAIDS. Cambodia Country Progress Report: Monitoring the Progress towards the Implementation of the Declaration of Commitment on HIV and AIDS. Reporting period: January 2010-December 2011. Prepared by National AIDS Authority for United Nations General Assembly Special Session (UNGASS) http://www.unaids.org/en/regionscountries/countries/cambodia/ (accessed 28 Dec 2012)

11. UNAIDS. HIV in Asia and the Pacific: Getting to Zero. 2011. http:// www.unaids.org/en/media/unaids/contentassets/documents/ unaidspublication/2011/20110826_APGettingToZero_en.pdf (accessed 20 Dec 2011).

12. Samnang $P$, Leng HB, Kim A, et al. HIV prevalence and risk factors among fishermen in Sihanouk Ville, Cambodia. Int J STD AIDS 2004;15:479-83.

13. Nishigaya K. Female garment factory workers in Cambodia: migration, sex work and HIV/AIDS. Women Health 2002;35:27-42.

14. Patterson D. Southeast Asia: national policy audits on HIV and migration. HIV AIDS Policy Law Rev 2005;10:31-3.

15. Hor LB, Detels R, Heng S, et al. The role of sex worker clients in transmission of HIV in Cambodia. Int J STD AIDS 2005;16:170-4

16. Maher L, Mooney-Somers J, Phlong P, et al. Selling sex in unsafe spaces: sex work risk environments in Phnom Penh, Cambodia. Harm Reduct J 2011;8:30

17. Plummer R. The sex industry in Cambodia: the traffic police. Economist 11 June 2009

18. UNIAP. United Nations Inter-Agency Project on Human Trafficking (Phase III). Cambodia: Exodus to the sex trade? Effects of the global financial crisis on women's working conditions and opportunities. Report. http://www.no-trafficking.org/reports_docs/ siren/siren_cb-04.pdf (accessed 31 Aug 2009).

19. UNAIDS pr. More women in Cambodia turning to sex trade amid financial crisis—UN report. 2009. http://www.un.org/apps/news/story. asp?News $\mid \mathrm{D}=31541 \& \mathrm{Cr}=$ human+trafficking $\& \mathrm{Cr} 1=$

20. KHANA. Mapping the pattern of sex workers, entertainment establishments, and men who have sex with men in Cambodia. Report by Hor Bun Leng, and Tuot Sovaranny, 2008 http://www. khana. org.kh/publicans-detail.php? mainid=\&pubid=23 (accessed 9 Jul 2011).

21. Kim AA, Sun LP, Chhorvann C, et al. High prevalence of HIV and sexually transmitted infections among indirect sex workers in Cambodia. Sex Transm Dis 2005;32:745-51.

22. Gorbach PM, Sopheab H, Chhorvann C, et al. Changing behaviors and patterns among Cambodian sex workers: 1997-2003. J Acquir Immune Defic Syndr 2006;42:242-7.

23. Ghys PD, Jenkins C, Pisani E. HIV surveillance among female sex workers. AIDS 2001;15(Suppl 3):S33-40.

24. Francis C. HIV prevention and anti-trafficking in conflict? The public health consequences of Cambodia's fight against trafficking. FHI (in collaboration with PSI, Care, UNAIDS) 2008.

25. FHI. SMARTgirl Program to Reduce Risk and Inspire Behavior Change. http://www.fhi.org/en/CountryProfiles/Cambodia/res SMARTgirl.htm\# (accessed 15 Jul 2011).

26. Burke KP, Munshaw S, Osburn WO, et al. Immunogenicity and cross-reactivity of a representative ancestral sequence in hepatitis $C$ virus infection. J Immunol 2012;188:5177-88.

27. Lamptey PR. Reducing heterosexual transmission of HIV in poor countries. BMJ Clin Res Ed 2002;324:207-11.
28. UNODC. Patterns and Trends of Amphetamine Type Stimulants and other drugs; Asis and the Pacific. The Global SMART Programme (Synthetics Monitoring: Analyses, Reporting, Trends), 2011. http:// www.unodc.org/unodc/en/scientists/smart.html (accessed 5 Jan 2012).

29. Ahmad K. Increased use of amphetamine-type stimulants threatens East Asian countries. Lancet 2002;359:1927.

30. Ahmad K. Asia grapples with spreading amphetamine abuse. Lancet 2003;361:1878-9.

31. Kulsudjarit K. Drug problem in southeast and southwest Asia. Ann N Y Acad Sci 2004;1025:446-57.

32. Farrell M, Marsden J, Ali R, et al. Methamphetamine: drug use and psychoses becomes a major public health issue in the Asia Pacific region. Addiction 2002;97:771-2.

33. Mongkolsirichaikul D, Mokkhavesa C, Ratanabanangkoon K. The incidence of amphetamine use among truck drivers from various regions of Thailand. J Med Assoc Thai 1988;71:471-4.

34. Vongsheree S, Sri-Ngam P, Ruchusatsawat N, et al. High HIV-1 prevalence among metamphetamine users in central Thailand, 1999-2000. J Med Assoc Thai 2001;84:1263-7.

35. Dayrit FM, Dumlao MC. Impurity profiling of methamphetamine hydrochloride drugs seized in the Philippines. Forensic Sci Int 2004:144:29-36.

36. Lin SK, Ball D, Hsiao CC, et al. Psychiatric comorbidity and gender differences of persons incarcerated for methamphetamine abuse in Taiwan. Psychiatry Clin Neurosci 2004;58:206-12.

37. Lua AC, Lin HR, Tseng YT, et al. Profiles of urine samples from participants at rave party in Taiwan: prevalence of ketamine and MDMA abuse. Forensic Sci Int 2003:136:47-51.

38. Razak MH, Jittiwutikarn J, Suriyanon V, et al. HIV prevalence and risks among injection and noninjection drug users in northern Thailand: need for comprehensive HIV prevention programs. J Acquir Immune Defic Syndr 2003;33:259-66.

39. Couture MC, Evans JL, Sothy NS, et al. Correlates of amphetamine-type stimulant use and associations with HIV-related risks among young women engaged in sex work in Phnom Penh, Cambodia. Drug Alcohol Depend 2012;120:119-26.

40. Melbye K, Khamboonruang C, Kunawararak $\mathrm{P}$, et al. Lifetime correlates associated with amphetamine use among northern Thai men attending STD and HIV anonymous test sites. Drug Alcohol Depend 2002;68:245-53

41. Sattah MV, Supawitkul S, Dondero TJ, et al. Prevalence of and risk factors for methamphetamine use in northern Thai youth: results of an audio-computer-assisted self-interviewing survey with urine testing. Addiction 2002:97:801-8.

42. Buavirat A, Page-Shafer K, Van Griensven GJ, et al. Risk of prevalent HIV infection associated with incarceration among injecting drug users in Bangkok, Thailand: case-control study. BMJ 2003;326:308.

43. Beyrer C, Razak MH, Jittiwutikarn J, et al. Methamphetamine users in northern Thailand: changing demographics and risks for HIV and STD among treatment-seeking substance abusers. Int J STD AIDS 2004; 15:697-704

44. Vanichseni S, Tappero JW, Pitisuttithum P, et al. Recruitment, screening and characteristics of injection drug users participating in the AIDSVAX B/E HIV vaccine trial, Bangkok, Thailand. AIDS 2004:18:311-16.

45. Maher L, Phlong P, Mooney-Somers J, et al. Amphetamine-type stimulant use and HIV/STI risk behaviour among young female sex workers in Phnom Penh, Cambodia. Int J Drug Policy 2011;22:203-9.

46. Kab V, Evans J, Sansothy N, et al. Testing for amphetamine-type stimulant (ATS) use to ascertain validity of self-reopted ATS use among young female sex workers in Cambodia. Masters Thesis for University of California Berkeley, School of Public Health, MPH in Epidemiology and Biostatistics. Completed May 152011.

47. Chattergoon MA, Levine JS, Latanich R, et al. High plasma interleukin-18 levels mark the acute phase of hepatitis $C$ virus infection. $J$ Infect Dis 2011;204:1730-40.

48. Yang C, Latkin C, Luan R, et al. Condom use with female sex workers among male clients in Sichuan Province, China: the role of interpersonal and venue-level factors. J Urban Health 2010;87:292-303.

49. Erausquin JT, Reed E, Blankenship KM. Police-related experiences and HIV risk among female sex workers in Andhra Pradesh, India. $J$ Infect Dis 2011;204(Suppl 5):S1223-8.

50. Shannon K, Kerr T, Allinott S, et al. Social and structural violence and power relations in mitigating HIV risk of drug-using women in survival sex work. Soc Sci Med 2008;66:911-21.

51. Shannon K, Kerr T, Strathdee SA, et al. Prevalence and structural correlates of gender based violence among a prospective cohort of female sex workers. BMJ 2009;339:b2939.

52. Kalichman SC, Simbayi LC, Kaufman M, et al. Alcohol use and sexual risks for HIV/AIDS in sub-Saharan Africa: systematic review of empirical findings. Prev Sci 2007;8:141-51. 
53. Morisky DE, Chiao C, Ksobiech K, et al. Reducing alcohol use, sex risk behaviors, and sexually transmitted infections among Filipina female bar workers: effects of an ecological intervention. J Prev Interv Community 2010;38:104-17.

54. Surratt HL, Inciardi JA. An effective HIV risk-reduction protocol for drugusing female sex workers. J Prev Interv Community 2010;38:118-31.

55. Argento E, Reza-Paul S, Lorway R, et al. Confronting structural violence in sex work: lessons from a community-led HIV prevention project in Mysore, India. AIDS Care 2011;23:69-74.

56. Reza-Paul S, Beattie T, Syed HU, et al. Declines in risk behaviour and sexually transmitted infection prevalence following a community-led HIV preventive intervention among female sex workers in Mysore, India. AIDS 2008;22(Suppl 5):S91-100.

57. Johnston LG, Sabin K, Mai TH, et al. Assessment of respondent driven sampling for recruiting female sex workers in two Vietnamese cities: reaching the unseen sex worker. J Urban Health 2006;83 (Suppl 6):i16-28

58. Baral S, Beyrer C, Muessig K, et al. Burden of HIV among female sex workers in low-income and middle-income countries: a systematic review and meta-analysis. Lancet Infect Dis 2012;12:538-49.

59. Merson M, Padian N, Coates TJ, et al. Combination HIV prevention. Lancet 2008:372:1805-6.

60. Abdool Karim Q, Abdool Karim SS, Frohlich JA, et al Effectiveness and safety of tenofovir gel, an antiretroviral microbicide, for the prevention of HIV infection in women. Science 2010;329:1168-74.

61. Grant RM, Lama JR, Anderson PL, et al. Preexposure chemoprophylaxis for HIV prevention in men who have sex with men. N Engl J Med 2010;363:2587-99.

62. Dworkin SL, Blankenship K. Microfinance and HIV/AIDS prevention: assessing its promise and limitations. AIDS Behav 2009;13: 462-9.

63. Pronyk PM, Kim JC, Abramsky T, et al. A combined microfinance and training intervention can reduce HIV risk behaviour in young female participants. AIDS 2008;22:1659-65.

64. Rosenberg MS, Seavey BK, Jules R, et al. The role of a microfinance program on HIV risk behavior among Haitian women. AIDS Behav 2011;15:911-18.

65. Evans J, Couture M-C, Stein ES, et al. Biomarker validation of recent unprotected sexual intercourse in a prospective study of young women engaged in sex work in Phnom Penh. Cambodia. Sex Transm Dis 2013;40:462-8.

66. Kab V, Evans J, Sansothy N, et al. Testing for amphetamine-type stimulant (ATS) use to ascertain validity of self-reported ATS use among young female sex workers in Cambodia. Addict Sci Clin Pract 2012;7:11-25.

67. Tucker JD, Tuminez AS. Reframing the interpretation of sex worker health: a behavioral-structural approach. $J$ Infect Dis 2011; 204(Suppl 5):S1206-10. 